\title{
ANNOUNCEMENT
}

(c) The Japan Wood Research Society 2013

\section{The 2nd Announcement of the 64th Annual Meeting of the Japan Wood Research Society in Matsuyama}

Date: March 13-15, 2014

Venue: Faculty of Education Main Bldg. Ehime University (Oral Presentation, Exhibition) and Himegin Hall Matsuyama city (Poster Presentation, Prize and Award Ceremony, Symposium), Matsuyama, Japan

The Japan Wood Research Society (JWRS) takes great pleasure in inviting all members of our society with an interest in the science and technology of wood to attend the 64th Annual Meeting of the JWRS that will be held from March 13 to 15 , 2014, Matsuyama city, Ehime, Japan.

The society members may make oral and poster presentations during the meeting. The symposium and the exhibition of the related companies will also be held. For more information please visit the following web site:

http://www.jwrs.org/wood2014/.

For the Organizing Committee: Prof. Dr. Sanro Tachibana (Chief), Faculty of Agriculture, Ehime University.

Prof. Dr. Masatoshi Sugimori (Executive Chief), Faculty of Agriculture,

Ehime University.

Associate Prof. Dr. Kazutaka Itoh (Secretary), Faculty of Agriculture,

Ehime University.

E-mail:wood2014@jwrs.org

Mokuzai Gakkaishi (Journal of the Japan Wood Research Society)

Mokuzai Gakkaishi is another official journal of the Japan Wood Research Society. This journal publishes original articles, notes, review articles, and announcements from the Society in Japanese but with English abstracts, tables, and figure captions for original reports. Contents of the latest issue of Mokuzai Gakkaishi are as follows:

Volume 59 Number 52013

\section{Category I}

T. Soma, Y. Suzuki, M. Inayama, N. Ando

Study of calculation method for timber drying time II: Measurement of convective heat transfer coefficient and experimental validation of proposed heat and mass transfer model

\section{Category II}

M. Miyamura, M. Ohta, M. Sato

Shearing strength and fracture mechanism of lath-mortar wall III: Strength and failure property of wall with opening

\section{Y. Yanagawa}

Results of outdoor exposure test for sugi glulam I: Shear strength and wood failure ratio
K. Ueda, I. Kamei, S. Kaneko, M. Araki, A. Kaneko, Y. Suimi, K. Tanaka, R. Kondo

Rapid degradation of pruned fruit-tree branches by a microbial preparation of Pycnoporus coccineus

K. Hitoe, T. Hasegawa, K. Hasegawa, K. Terazawa, K. Yamanaka, N. Hattori

Case study of life cycle assessment of domestic logs

H. Yamada, H. Yamauchi, S. Hidaka, Y. Kurimoto Mechanical properties and durability of short-rotation willow particleboards, harvested after single-year cultivation

\section{Category III}

N. Furuta, Y. Hirabayashi, T. Hirai

Bending and panel shearing deterioration of plywood used for the floor sheathing for a long period 